\title{
Risky behaviors of taxi drivers in Bandar Abbas, Iran
}

\author{
Asghar Razmara ${ }^{1}$, Teamur Aghamolaei ${ }^{2}$, Abdoulhossain Madani ${ }^{3}$, Zahra Hosseini ${ }^{4}$, Shahram Zare
}

${ }^{1} \mathrm{PhD}$ by Research Student, Social Determinants in Health Promotion Research Center, Hormozgan Health Institute, Hormozgan University of Medical Sciences, Bandar Abbas, Iran

${ }^{2}$ Professor of Health Education, Social Determinants in Health Promotion Research Center, Hormozgan Health Institute, Hormozgan University of Medical Sciences, Bandar Abbas, Iran

${ }^{3}$ Associate Professor of Epidemiology, Social Determinants in Health Promotion Research Center, Hormozgan Health Institute, Hormozgan University of Medical Sciences, Bandar Abbas, Iran

${ }^{4}$ Assistant Professor of Health Education and Promotion, Social Determinants in Health Promotion Research Center, Hormozgan Health Institute, Hormozgan University of Medical Sciences, Bandar Abbas, Iran

${ }^{5}$ Professor of Statistics, Department of Social Medicine, Medical School, Hormozgan University of Medical Sciences, Bandar Abbas, Iran

Type of article: Original

\begin{abstract}
Background and aim: It has been revealed that taxi drivers break more traffic rules than ordinary drivers. Such risky behaviors include stopping at prohibited areas and sudden change of direction. The present study aimed to determine the Risky Behaviors of Taxi Drivers in Bandar Abbas, Iran

Methods: In this cross-sectional study, 184 taxi drivers were randomly selected from eight taxi stations located at different parts of Bandar Abbas city in 2016. Taxi drivers' risky behaviors were evaluated via a 20 -item questionnaire. Data were analyzed by SPSS version 19, using descriptive statistics and independent-samples ttest. The p-values less than 0.05 were considered as statistically significant.

Results: The mean age of the drivers was $45.1( \pm 11.1)$ years. The mean of their occupational experience was 18.7 $( \pm 10.8)$ years. The risky behaviors which showed the highest frequency were respectively, failure to use signallights, driving too close to the cars in front, refusing to drive within the lanes and erratic lane changing.

The lowest frequency belonged to running a red light, ignoring 'no entry' signs and taking illegal U-turns. Risky driving behaviors were shown to be significantly more prevalent among drivers with previous experience of crashes or tickets than drivers with no such experiences $(\mathrm{p}<0.01)$.

Conclusion: Increasing the role of police supervision for the strict implementation of driving laws, and modification of the drivers' behavior and implementation of periodic training programs on drivers' safety issues can be considered for reducing taxi drivers' unsafe behaviors.

Keywords: Iran, Taxi drivers, Safety, Risky behaviors
\end{abstract}

\section{Introduction}

Road accidents are among the main public health problems, and annually threaten the lives of many people on a global scale. They cause 1.2 million deaths and 20-50 million cases of disability worldwide (1). According to the World Health Organization (WHO), road accidents are the ninth leading cause of mortality in all age groups. It is predicted that if no proper action be taken until 2030, mortalities caused by road accidents will be the seventh leading cause of death (2). In addition, according to the State Medical Law Organization statistics, in 2017, a total of 1,077 deaths occurred due to traffic accidents, out of which 322 deaths were due to intracity traffic accidents, 682

\section{Corresponding author:}

Professor Dr. Teamur Aghamolaei, Social Determinants in Health Promotion Research Center, Hormozgan Health Institute, Hormozgan University of Medical Sciences, Bandar Abbas, Iran.

Tel: +987633338583, Fax: +987633338584, E-Mail: teaghamolaei@gmail.com

Received: January 12, 2018, Accepted: March 19, 2018, Published: April 2018

iThenticate screening: March 14, 2018, English editing: April 05, 2018, Quality control: April 12, 2018

This article has been reviewed / commented by six experts

(C) 2018 The Authors. This is an open access article under the terms of the Creative Commons Attribution-NonCommercialNoDerivs License, which permits use and distribution in any medium, provided the original work is properly cited, the use is non-commercial and no modifications or adaptations are made. 
due to intercity traffic accidents, 70 due to rural road accidents, and two cases were unknown (3). The developing urbanism has resulted in the advanced public taxi transportation systems. Moreover, it has been revealed that taxi drivers break more traffic rules than ordinary drivers. Such risky behaviors include stopping at prohibited areas and sudden change of direction (4). An investigation revealed that annually $20 \%$ of taxi drivers have car accidents, which accounts for a high proportion of the total rate of traffic accidents (5). In Iran, a study showed that the frequency of unsafe behaviors of taxi drivers in Tehran was about 52.5\% (6). Previous studies have also revealed a high level of risky behaviors including excessive speeding, unfastened seat belts, illegal overtakes, stopping in prohibited areas to pick up or drop off passengers, allowing passengers in while moving, shifting lanes repeatedly, and moving too close to the car in front (7-9). Risky driving behaviors are positively correlated with the occurrence of car accidents (10). Therefore, any attempt to change these behaviors will result in reducing the rate of accidents. On the other hand, any intervention to correct risky driving behaviors requires sound knowledge and analysis of such behaviors. Despite the extensive body of research on risky driving behaviors of various vehicles (11-14), this issue still needs more investigation as there is no comprehensive research on the taxi drivers' risky behaviors (1517). As driving behavior is a part of cultural behavior, car accidents will not be reduced unless the risky driving behaviors of different cultures and geographical areas are explored and addressed sufficiently. The past decade has seen few violations of driving rules by taxi drivers. However, taxi drivers' risky behaviors are still a big challenge (4). Taxi drivers tend, more than ordinary drivers, to show risky behaviors and they even enjoy it (7). Therefore, the present research aimed to determine the current state of Iranian taxi drivers' risky behaviors in Bandar Abbas, Iran.

\section{Material and Methods}

\subsection{Research Design and Participants}

This cross-sectional research was performed in 2016. The target population of the present research was the taxi drivers of Bandar Abbas city. The sample size was determined to be 184, according to the previous literatures (18). The participants were selected from taxi stations.

\subsection{Selection criteria}

\subsubsection{Inclusion criteria}

Those who entered the study had at least one year of taxi driving experience and were members of the Bandar Abbas taxi driving union. They were capable of reading and writing and were permanent residents of Bandar Abbas.

\subsubsection{Exclusion criteria}

Exclusion criteria in this study were having less than one year of taxi driving experience, unwilling to participate in the study, and giving incomplete responses to the questions.

\subsection{Instrument}

The questionnaire was developed through interviewing taxi drivers and traffic officers, studying and reviewing traffic regulations of Iran, and reviewing previous studies on driving accidents. This questionnaire comprised of two sections. The first section consisted of demographic information (age, education, driving experience, taxi driving experience, experience of being fined for breaking driving rules, and experience of accidents). The second section consisted of 20 items regarding risky driving behaviors. Among these risky behaviors were talking or texting on the phone while driving, unfastening the seat belt, speeding, running a red light, illegal overtaking, not respecting priorities, and entering 'no entry' streets. Each item asked the respondent whether he had ever displayed any of the risky driving behaviors or not. The answers could be chosen from three options: often, sometimes, and never which were respectively scored 2, 1 and 0 . Then, the overall score would be the sum of all scores. According to the total number of questionnaire questions and their score, each participant's risky behaviors score should be between 0 and 40. A higher overall score would imply more risky driving behaviors.

\subsection{Validity and reliability}

The questionnaire was checked for content validity by a panel of experts. To this aim, the questionnaire was given to 8 experts with specialty in health education and traffic safety behaviors. They were asked to comment on the clarity, simplicity, and relevance of the items. If less than half of the panel members agreed on an item in terms of the specified criteria, that item would be either edited or removed. According to the panel's decision, no item was removed from the primary version of the questionnaire, but a few were revised. To assess the reliability of the questionnaire, the test-retest method was used. To this aim, the questionnaire was given to 15 taxi drivers two times, with an interval of two weeks. Then, the correlation coefficient of their responses was estimated. The correlation coefficient of the responses was found to be 0.83 which shows a good reliability. Before initiating the research, the 
http://www.ephysician.ir

required permissions were taken from the taxi drivers' union and they were ensured of the confidentiality of the data.

\subsection{Procedure}

Initially, twenty four taxi stations were identified in different parts of Bandar Abbas city and out of which, eight stations were randomly selected. The number of subjects of each station was determined according to the approximate total number of the station's drivers. The stations were visited twice, once in the morning and once again in the evening, to do the sampling. The first driver entering each station was included in the study sample if he met the inclusion criteria and consented to take part in the research. Afterwards, every fifth driver entering the station was selected until the required sample size was met. The questionnaires were completed by drivers while being supervised by the researchers. If the respondents faced a vague question, the researchers would help them to understand the question correctly.

\subsection{Ethic approval}

This study was approved by the Ethics Committee of Hormozgan University of Medical Sciences (Code: HUMS.REC.1396.38). Before data collection, the purpose of the study was explained to the participants and an informed consent was obtained verbally. Participants were free to leave the study at any stage, with no explanation needed. Participation in the research did not put any financial burden on the participants. The data collected was kept confidential through codes.

\subsection{Data Analysis}

The data were statistically analyzed by SPSS software version 19 (IBMC Corp., Armonk, NY, USA). The descriptive statistics (frequency, mean, and standard deviation) were used to describe the data. Independent-samples t-test was used to compare drivers' risky behaviors between the different groups. The p-values less than 0.05 were considered statistically significant.

\section{Results}

From184 distributed questionnaires, 180 were completed and returned to be analyzed (response rate $=97.8 \%$ ). The mean age of the participants was 45.1 years $(\mathrm{SD}=11.1)$, the mean of their driving experience was 18.7 years $(\mathrm{SD}=10.8)$ and the mean of their experience as a taxi driver was 10.3 years $(\mathrm{SD}=7.5)$.

Table 1. Risky driving behaviors of taxi drivers in Bandar Abbas

\begin{tabular}{|c|c|c|c|c|c|c|}
\hline \multirow[t]{2}{*}{ Behavior } & \multicolumn{2}{|c|}{ Often } & \multicolumn{2}{|c|}{ Sometimes } & \multicolumn{2}{|c|}{ never } \\
\hline & $\mathrm{n}$ & $\%$ & $\mathrm{n}$ & $\%$ & $\mathrm{n}$ & $\%$ \\
\hline Talking or texting on phone while driving & 3 & 1.7 & 60 & 34.1 & 118 & 64.2 \\
\hline Unfastening seat belt while driving & 4 & 2.2 & 22 & 12.2 & 155 & 85.6 \\
\hline Eating, drinking or smoking while driving & 2 & 1.7 & 32 & 17.7 & 147 & 81.2 \\
\hline Excessive speeding & 3 & 1.7 & 18 & 9.9 & 160 & 88.4 \\
\hline Fatigue and drowsiness while driving & 1 & 0.6 & 20 & 11.0 & 160 & 88.4 \\
\hline Running a red light & 0 & 0 & 13 & 7.2 & 168 & 92.8 \\
\hline $\begin{array}{l}\text { Using high beams at night facing other cars approaching in the opposite } \\
\text { direction }\end{array}$ & 1 & 0.6 & 30 & 16.5 & 150 & 82.9 \\
\hline Carrying too many passengers & 1 & 0.6 & 34 & 18.8 & 146 & 80.7 \\
\hline Staying too close to the car in front & 21 & 11.6 & 41 & 22.7 & 119 & 65.7 \\
\hline Erratic lane changing while driving & 12 & 6.6 & 27 & 14.9 & 142 & 78.5 \\
\hline Failure to drive within the lanes & 19 & 10.5 & 28 & 15.5 & 134 & 74.0 \\
\hline Failure to use signal-lights & 24 & 13.3 & 28 & 15.5 & 129 & 71.3 \\
\hline Reversing in a dangerous situation & 3 & 1.7 & 44 & 24.3 & 134 & 74.0 \\
\hline Entering 'No entry' streets & 0 & 0 & 13 & 7.2 & 168 & 92.8 \\
\hline Taking illegal U-turns & 0 & 0 & 11 & 6.1 & 170 & 93.9 \\
\hline Illegal overtaking along two-way streets & 2 & 1.1 & 19 & 10.5 & 160 & 88.4 \\
\hline Failure to give way to other cars & 2 & 1.1 & 51 & 28.2 & 128 & 70.7 \\
\hline Stopping at prohibited sites to let passengers in or out & 1 & 0.6 & 62 & 34.3 & 118 & 65.2 \\
\hline Overtaking a car on the right side & 2 & 1.1 & 17 & 9.4 & 162 & 89.5 \\
\hline Deviation to the left side while driving & 1 & 0.6 & 20 & 11.0 & 160 & 88.4 \\
\hline
\end{tabular}


According to the results, $22.2 \%$ of the participants had the experience of accidents and $30.6 \%$ had been fined while transporting passengers. In total, $3.3 \%$ of the participants were illiterate; $19.4 \%$ had elementary school education; $38.9 \%$ had high school education; $30.6 \%$ had a diploma, and $7.8 \%$ had an academic degree. The highest frequency of violations were found to be failure to use the signal-lights and moving too close to the car in front, failure to drive within the lanes, and erratic lane changing movements were next in order. The lowest frequencies belonged to running a red light, entering 'no entry' streets, and taking illegal U-turns, in that order (Table 1). The mean score of risky driving behaviors in the whole sample was $4.33(\mathrm{SD}=3.1)$ and it ranged from 0 to 15 . The risky behaviors score was significantly higher in drivers with previous experience of driving fines $(p<0.001)$. Moreover, the rate of risky driving behaviors in drivers with an experience of car crash was significantly higher than those without it $(\mathrm{p}<0.001)$ (Table 2). There was no significant correlation between age and driving with risky behaviors, based on one-way ANOVA test $(r=-0.06, p=0.52)$. Also, there was no significant relationship between risky behaviors and driving experience and educational level $(\mathrm{F}=0.84, \mathrm{p}=0.52)$.

Table 2. Comparison of risky driving behaviors among taxi drivers in terms of their experience of fines and car crashes

\begin{tabular}{|l|l|l|l|l|}
\hline \multicolumn{2}{|l|}{ Variable } & Mean \pm SD & $t^{*}$ & p-value \\
\hline Experience of fine & Yes & $5.51 \pm 3.1$ & 3.25 & $<0.001$ \\
\cline { 2 - 3 } & No & $3.89 \pm 3$ & & \\
\hline \multirow{2}{*}{ Experience of car crash } & Yes & $5.43 \pm 2.9$ & 2.43 & $<0.001$ \\
\cline { 2 - 3 } & No & $4.07 \pm 3.1$ & & \\
\hline
\end{tabular}

*Independent-samples t-test

\section{Discussion}

The present research aimed to determine the Risky Behaviors of Taxi Drivers in Bandar Abbas, Iran. Recognition of such behaviors and planning to correct them can have a significant effect on reducing violations of law and car crashes. Contrary to the expectations of the researchers in this study, there was no significant relationship between age and driving with risky behaviors, which is consistent with the results of some other studies $(17,19,20)$. But another study showed that the probability of an accident reduces by increasing the drivers' age. The mentioned study showed that for each year of age increase, the probability of an accident reduces by $2 \%$ (21). Other studies have shown a significant relationship between age and driving with risky behaviors $(22,23)$. Our findings, in this part, can be explained by the fact that the target group in this study, regardless of which age group they belong to, consider themselves as professional and experienced drivers and it makes them susceptible of performing risky behaviors. An explanation for discrepancies between our findings and the results of the studies in other countries can be differences in the legal age limit for obtaining a driver's license in the different countries. According to the results, there was no significant relationship between education and driving with risky behaviors; which is consistent with the results of some other studies $(21,22)$. But in another study, drivers with a lower educational level were more likely to commit unsafe driving behaviors (20). One of the possible causes of this difference may be the different age range and educational level of the drivers in various studies. For example, younger drivers are likely to have higher levels of education and receive new and up-to-date driver's licenses and subsequently, they are less likely to commit risky behaviors.

In this study, failure to use signal lights when starting on a journey or before pulling over was found to be the most prevalent risky behavior among taxi drivers. Using signal lights is one way to let other drivers know you are about to go or about to pull over. If used appropriately, it can significantly reduce the risk of accidents. A research in the Chinese context indicated that $40 \%$ of the drivers use signal lights while changing directions (24). Signal lights might be the least frequently used internal parts of a car. However, failure to apply them can be the main cause of many accidents. Though the law has set certain fines to react against risky driving behaviors, failure to use signal lights is often not considered by the police due to the heavy traffic or the low number of police officers available in streets. Therefore, a driver might ignore using signal lights as there is often no fine. Among other probable reasons for risky behaviors of taxi drivers are personality traits, psychological characteristics, attitude towards these behaviors, and social status of the taxi drivers. It is likely that taxi drivers are experienced enough to be aware of risky driving behaviors and their consequences. However, it seems that factors other than a lack of knowledge are involved in such behaviors. In an investigation, Hassen stated that knowledge is not a predictor of risky driving behaviors (19). Attitude can probably be a stronger factor than knowledge to help to predict driving behaviors. A body of research confirmed this finding and revealed that those with a negative attitude toward safe driving behaviors, show riskier behaviors $(17,25)$. 
According to the findings of this study, Moving too close to the car in front, failure to drive within the lanes, and erratic lane changing were the other high frequency violations, which is in line with the results of similar studies (6, $16,26)$. A driver is required to keep a certain distance from the car in front. If the right distance is not kept, the driver would have no adequate time to brake and show the right reaction, and would therefore hit the car in front. The U.S. national highway traffic safety administration (NHTSA) reported that more than $30 \%$ of car accidents were related to cars bumping the back of other cars (27). Zangiabadi and Gashti reported that not keeping a proper distance from the car in front is the cause of $9 \%$ of accidents in Isfahan (28). Such risky behavior can be explained by the fact that taxi drivers' income is strongly affected by the number of passengers they carry. Thus, to carry more passengers and earn more money, they try to drive as fast as possible and it causes them commit risky behaviors such as not keeping the proper distance from the car in front. Another reason might be that taxi drivers perceive themselves as professional and highly experienced drivers. It makes them to feel invulnerable to accidents. This hypothesis is supported by some research which revealed that more experienced drivers tend to show riskier behaviors while driving (29). In this regard, more experienced taxi drivers probably rely more on their personal skills and capabilities rather than rules and regulations. Contrarily, some other investigations have shown that drivers' experience could not predict risky driving behaviors $(19,30)$. Taxi drivers are required to drive between lane markings. They are prohibited from making erratic lane changing movements. A great proportion of intracity car accidents are caused by erratic lane changing movements and frequent shifting between the lanes. The drivers have been prohibited from making erratic lane changing movements in the streets. If they need to shift lane, they should use their indicators and slowly and securely shift lane. For all this to happen in the right way, the required infrastructures should be provided. As an instance, the streets are required to have appropriate, standard, and visible lane markings. These markings are expected to have been painted in white on the streets and highways so as to be clearly visible for all drivers. If the required infrastructure does not exist, drivers cannot be expected to show correct behaviors. On the other hand, there is an emphasis on the right administration of traffic rules as it is a key component involved in reducing the rate of driving accidents and their consequences. According to the WHO, the fully attentive administration of traffic rules has been only realized in 35 countries around the world (31). It is likely that the presence of an adequate number of traffic police officers in a certain area could significantly reduce the rate of traffic violations. Human factors are among the main causes of the majority of car accidents. Thus, special attention needs to be paid to the underlying sociological, psychological, and cultural issues. Regarding this issue, an investigation revealed that social factors are strongly involved in the occurrence of taxi drivers' risky driving behaviors (32). In their research, Jafarpour et al. pinpointed the role of cultural issues in risky driving behaviors (33). Acculturating the act of driving between the lane markings in the street would require a long period of time and cannot be reached only through raising fines in the short-term. Although fines can strongly influence drivers to get used to obeying traffic rules, they are not sufficient. Many factors need to be taken into account to promote safe driving behaviors and stop risky driving behaviors. According to the present findings, running a red light, entering 'no entry' streets, and taking illegal U-turns are shown to be the least frequent risky driving behaviors. These findings are consistent with an Adl et al. study (6). Not running a red light can be explained by the presence of police closely monitoring intersections as well as the traffic cameras installed there to record cases of violations. The risk of receiving traffic fines can be yet another underlying reason for not running a red light. It seems that higher fines and more severe penalties for traffic rule violations in recent years have resulted in the reduction of the rate of risky behaviors. Another reason can be that taxi drivers might be unable to afford the fines and penalties and this might have affected the rate of risky driving behaviors among taxi drivers. In this regard, another study showed that paying more money to taxi drivers will lead to a significant increase in the rate of traffic rule violations (19).

As the results of the present research showed, the rate of risky driving behaviors was significantly higher among taxi drivers with an experience of accidents. It was observed that their experience did not reduce their risky behaviors. Similarly, some other studies in Turkey indicated that there was no change of behavior in taxi drivers who had previous experience of accidents as they attributed the cause of the accident to fate or bad luck rather than themselves (34). The present findings are consistent with those reported by Hassen (19). In such cases, it might be recommended to focus on changing taxi drivers' behaviors. Probably, an effective way to change their behaviors would be to appeal to highly influential characters in their job including well-known experienced drivers. It was observed in a study in Sweden that peers managed to positively affect the rate of risky driving behaviors (35). Some other researches, similarly, showed the effective role of coworkers in reducing risky driving behaviors (36). Moreover, the present findings revealed that the rate of risky behaviors was significantly higher in drivers with a previous experience of traffic fines. Traffic fines and penalties appear to be ineffective in making the drivers obey the law. Thus, to reduce risky driving behaviors, besides fines and penalties, other measures such as participation of the target group in law-making processes and close affinity of law administrators with the target group to justify the 
rules and persuade them to obey the laws are recommended. One limitation of the present research was the selfreported information in data collection process which can raise the question of data accuracy. Another limitation is that as the target population was taxi drivers, the results cannot be generalized to all drivers.

\section{Conclusions}

The findings of this study showed that the most frequent risky behaviors of taxi drivers are not using signal lights, the lack of proper distance between the moving cars, not driving within the lanes, and the zigzag movements. These behaviors were higher among the drivers who had a history of fines and car accidents. Awareness of hazardous driving behaviors in this group and planning to correct them can have a good impact on reducing traffic violations and accidents. The careful supervision of traffic by the police, the strict implementation of driving laws, and periodic training programs on driving safety issues are recommended to reduce unsafe driving behaviors. It is suggested that researchers in future studies, through qualitative and in-depth studies, identify the underlying factors involved in drivers' risky behaviors for implementation of effective interventions. Also, other studies aiming to change and improve drivers' awareness, attitudes, and perceptions are recommended. Risky driving behavior is multifaceted phenomenon and is affected by a wide range of factors. To reduce the rate of such behaviors among taxi drivers, there is a need to consider some issues including necessary facilities and infrastructure for safe driving, consideration of personal, social and cultural issues, development of a positive driving attitude, setting close affinity of the authorities with drivers, and more serious monitoring by the police.

\section{Acknowledgments:}

The present article is based on the research doctoral thesis, sponsored by Bandar Abbas University of Medical Sciences. The authors would like to acknowledge the Center for the Development of Clinical Research at Shahid Mohammadi Hospital, for consulting in the proposal design and all staff of the taxi driving company, and the taxi drivers of Bandar Abbas city who helped us in the conduction of this study.

\section{Conflict of Interest:}

There is no conflict of interest to be declared.

\section{Authors' contributions:}

All authors contributed to this project and article equally. All authors read and approved the final manuscript.

\section{References:}

1) Rezaei S, Arab M, Karami Matin B, Akbari Sari A. Extent, consequences and economic burden of road traffic crashes in Iran. J Inj Violence Res. 2014; 6(2): 57. doi: 10.5249/Jivr.V6i2.191. PMID: 24045158, PMCID: PMC4009170.

2) WHO. Global status report on road safety 2015. World Health Organization; 2015.

3) Iranian Legal Medicine organization. Statistics of deaths and injuries resulting from traffic accidents. 2017. Available from: http://www.lmoir/indexaspx?siteid=1\&pageid=2370.

4) Jiawei W. Analysis of taxi drivers' driving behavior based on a driving simulator experiment. Stars. 2014. Available from: http://stars.library.ucf.edu/etd/4587/.

5) Shi J, Tao L, Li X, Xiao Y, Atchley P. A survey of taxi drivers' aberrant driving behavior in Beijing. Journal of Transportation Safety \& Security. 2014; 6(1): 34-43. doi: 10.1080/19439962.2013.799624.

6) Adl J, Dehghan N, Abbaszadeh M. The survey of unsafe acts as the risk factors of accidents in using taxis for intercity travelling in Tehran. Safety promotion and injury prevention (Tehran). Journal of Safety Promotion And Injury Prevention. 2014; 2(1): 39-46.

7) Burns PC, Wilde GJ. Risk taking in male taxi drivers: Relationships among personality, observational data and driver records. Personality and Individual Differences. 1995; 18(2): 267-78. doi: 10.1016/01918869(94)00150-Q.

8) Rosenbloom $\mathrm{T}$, Shahar A. Differences between taxi and nonprofessional male drivers in attitudes towards traffic-violation penalties. Journal of Transportation Research. 2007; 10(5): 428-35. doi: 10.1016/J.Trf.2007.04.002.

9) Shams M, Shojaeizadeh D, Majdzadeh R, Rashidian A, Montazeri A. Taxi Drivers' Views About Risky Driving Behaviors In Tehran: A Qualitative Study Using A Social Marketing Approach. Accid Anal Prev. 2011; 43(3): 646-51. doi: 10.1016/j.aap.2010.10.007. PMID: 21376850. 
10) Morowati Sharifabad MA. The Health Belief Model variables as predictors of risky driving behaviors among commuters in Yazd, Iran. Traffic injury prevention. 2009; 10(5): 436-40. doi: 10.1080/15389580903081016. PMID: 19746307.

11) Hatamzadeh N, Nazari M, Ghahramani L. Impact of Educational Intervention on Seat Belt Use among Drivers Based on Health Belief Model. Toloo-E-Behdasht. 2012; 11(3): 45-55.

12) Knowlden AP, Sharma M. Health Belief Model predictors of undergraduate students' engagement in short messaging services while operating a motor vehicle. Safety Science Monitor.

13) Quine L, Rutter DR, Arnold L. Predicting and understanding safety helmet use among schoolboy cyclists: a comparison of the theory of planned behaviour and the health belief model. Psychology and Health. 1998; 13(2): 251-69. doi: 10.1080/08870449808406750.

14) Tavafian SS, Aghamolaei T, Gregory D, Madani A. Prediction of seat belt use among Iranian automobile drivers: application of the theory of planned behavior and the health belief model. Traffic injury prevention. 2011; 12(1): 48-53. doi: 10.1080/15389588.2010.532523. PMID: 21259173.

15) Husain NA, Mohamad J, Idris MA. Antecedents on safety behaviour of taxi drivers from work psychological perspectives. Malaysia International Technical Conference: Seoul, Korea. 2014; Nov 17-19.

16) Khalafi A, Mohammadian Y, Malekpour F, Malekpour Ar, Sarfaraz D, Zeynelzadeh M. Relationship between attitude to safety and dangerous behaviors of interior taxi drivers of Urmia city. Journal Of Torbat Heydariyeh University Of Medical Sciences. 2013; 1(3): 43-9.

17) Majdzadeh R, Rashidian A, Shams M, Shojaeizadeh D, Montazeri A. Using the social marketing model to reduce risky driving behaviors among taxi drivers in Tehran. Journal of School of Public Health and Institute of Public Health Research. 2011; 9(2): 21-40.

18) Paris H, Van den Broucke S. Measuring cognitive determinants of speeding: An application of the theory of planned behaviour. Transportation Research. 2008; 11(3): 168-80. doi: 10.1016/J.Trf.2007.09.002.

19) Hassen A, Godesso A, Abebe L, Girma E. Risky driving behaviors for road traffic accident among drivers in Mekele city, Northern Ethiopia. BMC research notes. 2011; 4(1): 535. doi: 10.1186/1756-0500-4-535. PMID: 22166174, PMCID: PMC3253774.

20) Malekpour F, Mohammadian Y, Malekpour AR. Investigation of the relationship between personality and attitude to safety of taxi drivers. Journal Of Safety Promotion And Injury Prevention. 2014; 2(3): 204-8.

21) Alavi SS, Mohammadi MR, Soori H, Jannatifard F, Mohammadi-Kalhory S. The determination of Cognitive-behavioral features of bus and Truck drivers during road accidents in 2013-2014. Safety Promotion and Injury Prevention. 2016; 3(4): 223-32.

22) Mazloomi S, Moradi M, Fallahzade H, Zare A, Khoshakhlagh A, Barzegarpour V. The Study of Dangerous Behavior of Drivers in the Yazd City in 2013. Tolooe Behdasht. 2016; 14(6): 14-23.

23) Shen B, Qu W, Ge Y, Sun X, Zhang K. The relationship between personalities and self-report positive driving behavior in a Chinese sample. PLoS one. 2018; 13(1): e0190746. doi: 10.1371/journal.pone.0190746. PMID: 29324823, PMCID: PMC5764283.

24) Zhang W, Huang YH, Roetting M, Wang Y, Wei H. Driver's views and behaviors about safety in ChinaWhat do they NOT know about driving? Accident Analysis \& Prevention. 2006; 38(1): 22-7. doi: 10.1016/j.aap.2005.06.015. PMID: 16061188 .

25) Chen CF. Personality, safety attitudes and risky driving behaviors-evidence from young Taiwanese motorcyclists. Accident Analysis \& Prevention. 2009; 41(5): 963-8. doi: 10.1016/j.aap.2009.05.013. PMID: 19664433.

26) Shams M, Majdzadeh S, A. M. Hazardous behavior in taxi drivers at Tehran city: attitude, self-reported and observational behaviour. Payesh. 2010; 9(4).

27) Administration NHTS. Traffic safety facts 2013: a compilation of motor vehicle crash data from the fatality analysis reporting system and the general estimates system. Transportation Research Board. 2015; 812: 139.

28) Zangi Abadi A, Gashti KH. The survey of accidents cuases in highways: a case study in urban highways at Isfahan city. Rahvar studies. 2011; 9(17).

29) Males M. Traffic crash victimizations of california children and teenagers by drinking over-21 drivers. Californian Journal of Health Promotion. 2009; 7(2). PMID: 20409428.

30) Komba DD. Risk factors and road traffic accidents in Tanzania: A case study of Kibaha District: Fakultet for samfunnsvitenskap og teknologiledelse. 2007.

31) WHO. Global status report on road safety 2013: supporting a decade of action: World Health Organization; 2013. 
32) Rad M, Martiniuk AL, Ansari-Moghaddam A, Mohammadi M, Rashedi F, Ghasemi A. The pattern of road traffic crashes in South East Iran. Global journal of health science. 2016; 8(9): 149. doi: 10.5539/gjhs.v8n9p149. PMID: 27157159, PMCID: PMC5064071.

33) Jafarpour S, Rahimi-Movaghar V. Determinants of risky driving behavior: a narrative review. Medical journal of the Islamic Republic of Iran. 2014; 28: 142. PMID: 25695000, PMCID: PMC4322337.

34) Yılmaz V, Çelik HE. Risky driving attitudes and self-reported traffic violations among Turkish drivers: The case of Eskişehir. Dogus University Journal. 2006; 7(1): 127-38.

35) Åberg L. Drinking and driving: intentions, attitudes, and social norms of Swedish male drivers. Accident Analysis \& Prevention. 1993; 25(3): 289-96. doi: 10.1016/0001-4575(93)90023-P. PMID: 8323663.

36) Pradhan AK, Li K, Bingham CR, Simons-Morton BG, Ouimet MC, Shope JT. Peer passenger influences on male adolescent drivers' visual scanning behavior during simulated driving. J Adolesc Health. 2014; 54(5): S42-9. doi: 10.1016/J.Jadohealth.2014.01.004. PMID: 24759440, PMCID: PMC3999411 